\title{
AVALIAÇÃO DOCENTE: MONITORAMENTO DO TRABALHO DOS PROFESSORES EM PORTUGAL
}

\section{CELY DO SOCORRO COSTA NUNES}

\section{RESUMO}

O estudo centrou-se na análise de documentos oficiais que versam sobre avaliação do desempenho docente emitidos pelo Ministério de Educação e Ciência de Portugal no período de 2009 a 2012. Parte-se do pressuposto de que tais documentos respondem a uma política oficial de avaliação docente de cunho somativo e meritocrático, cujos padrões de desempenho revelam uma política nacional de controle, orientação, monitoramento, supervisão do trabalho dos professores que se reflete na profissionalização docente.

PALAVRAS-CHAVE AVALIAÇÃO DOCENTE - PADRÃO DE DESEMPENHO • POLÍTICA EDUCACIONAL. 


\section{RESUMEN}

El estudio se centró en el análisis de documentos oficiales que versan sobre la evaluación del desempeño docente, expedidos por el Ministerio de Educación y Ciencia de Portugal en el período de 2009 a 2012. Se parte del presupuesto de que dichos documentos responden a una política oficial de evaluación docente de carácter sumatorio y meritocrático, cuyos estándares de desempeño revelan una política nacional de control, orientación, monitoreo y supervisión del trabajo de los profesores que se refleja en su profesionalización.

PALABRAS CLAVE EVALUACIÓN DEL PROFESOR • ESTÁNDAR DE RENDIMIENTO • POLÍTICA EDUCATIVA.

\section{ABSTRACT}

The study focused on the analysis of official documents that deal with the assessment of teacher performance, which were issued by the Ministry of Education and Science of Portugal in the period from 2009 to 2012. The underlined assumption is that these documents respond to an official policy of teacher assessment that has summative and meritocratic nature. Besides, it is expected that standards of performance reveal a national policy of control, guidance, monitoring, and supervising the work of teachers, which is reflected in teacher professionalization.

KEYWORDS TEACHER ASSESSMENT - STANDARDS OF

PERFORMANCE • EDUCATION POLICY. 


\section{INTRODUÇÃO}

A avaliação de desempenho dos educadores de infância e dos professores dos ensinos públicos básico e secundário está no centro das reformas educativas em Portugal como forma de se obterem informações credíveis e fiáveis da qualidade do trabalho docente e do sistema de ensino.

Se, anterior à revolução democrática de 1974, ela era desenvolvida de forma assistemática pelo poder estatal porque não era considerada uma atividade essencial para a melhoria da qualidade do ensino (ALVES; MACHADO, 2010), nos idos dos anos 90 do século passado, na sequência da Lei de Bases do Sistema Educativo português n. 46/86, de 14 de outubro, a Avaliação de Desempenho Docente (ADD) reaparece de modo mais sistemático nas políticas educativas com propó-

1 Para um estudo da evolução das políticas de avaliação de desempenho docente em Portugal, suas cacterizações, finalidades, alterações e consequências, consultar: Simõe (1998), Curado (2002), Pereira (2011), Formosinho e Machado (2010a, 2010b), Nunes e Rodrigues (2011) sitos distintos ${ }^{1}$ tornando-a um campo mais exigente e com maiores consequências para o desenvolvimento da carreira. Assim, se em sua gênese, ainda sob a tutela de Marquês de Pombal, e em sua continuidade ao longo dos tempos, a ADD em Portugal era feita por inspetores, de forma centralizadora e marcada por uma função reguladora, atualmente 
ela é projetada com função de classificação, certificação e seleção em um sistema de reconhecimento do mérito e da excelência, com a qual não há nenhum efeito prático para a progressão na carreira, pois o Estado congelou a progressão nas carreiras dos trabalhadores da administração pública e, supostamente, para a melhoria da prática docente, do ensino e da escola.

O conjunto do professorado reconhece a importância da ADD quando é orientada por funções formativas tendo em vista o desenvolvimento profissional. Contudo, como não é esse o modelo em causa na realidade portuguesa, na arena social, ela tem se revelado conflituosa, contestada pelos professores, de difícil concepção e complexa operacionalização nos últimos anos (FERNANDES, 2008; NUNES, 2011; PEREIRA, 2011), o que nos leva a acentuar que a ADD é um campo de poder e de contestação por ser um campo político em que transitam diferentes e, por vezes, antagónicos valores e juízos sobre o que caracteriza um sistema de avaliação de professores mais pertinente e adequado às finalidades que os orientam.

Este artigo $^{2}$ toma como material de análise documentos oficiais emitidos pelo governo português como forma de problematizar a atual política de ADD no que se refere aos Padrões de Desempenho Docente (PDD), o qual, do meu ponto de vista, assenta-se em uma lógica que serve como instrumento de controle e monitoramento do trabalho de docentes, em que estes são responsabilizados pela sua performance e resultados, cuja materialidade ainda está longe de contribuir para a reflexividade e o desenvolvimento profissional.

\section{A AVALIAÇÃO DOCENTE: ENTRE DUAS LÓGICAS}

O professor tem sido nos últimos tempos um profissional do qual mais se tem exigido a qualidade do trabalho, bem como a de sua formação, sob o argumento de que são campos indispensáveis para a melhoria da qualidade do ensino, das aprendizagens dos alunos e, consequentemente, da melhoria do sistema educativo. Essa exigência torna-se mais
2 Decorrente do projeto de investigação "A inevitabilidade da avaliação escolar e do desempenho docente em Portugal: processos, tensões e desafios", coordenado pela autora e desenvolvido no âmbito da Unidade de Investigação e Desenvolvimento em Educação e Formação (Uidef) do Instituto de Educação da Universidade de Lisboa. 
3 Pisa (Programme for International Student Assessment), lançado em 1997, é aplicado em todos os países integrantes da OCDE e em 32 outros países que aderiram ao projeto, é um estudo de avaliação independente, que permite informar os governos e os cidadãos sobre o desempenho dos sistemas educativos dos países participantes. $O$ estudo avalia as competências básicas dos alunos de 15 anos nos domínios considerados essenciais: Leitura Matemática e Ciências

4 Para uma leitura dessa realidade confira Murillo Javier (2007) contundente sobretudo quando os resultados de avaliações externas nacionais (exames nacionais) e internacionais, como, por exemplo, o Programa Internacional de Avaliação de Estudantes (Pisa), ${ }^{3}$ conduzido pela Organização para a Cooperação e Desenvolvimento Econômico (OCDE), informam a baixa qualidade do desempenho desses sistemas por meio do desempenho dos alunos em que a deficiência das aprendizagens dos estudantes é atribuída à fragilidade do ensino. Como os resultados dessas avaliações têm sido utilizados por diversos governos como parâmetro para a definição e/ou refinamento de políticas educativas, não é de se estranhar que o Estado passe a consagrar especiais atenções ao aprofundamento da qualidade do trabalho dos professores e de sua formação, a quem cabe assegurar e, sobretudo, manter um ensino com melhor produtividade e resultado. Sendo assim, esses professores necessitam de ser cuidadosamente controlados e monitorados (VIEIRA; MOREIRA, 2011).

Nesse sentido, formação (inicial e continuada) e trabalho docente associam-se, muitas vezes, para justificar o investimento no ensino pelo ente público, pelas escolas ou pelos próprios professores, consagrando-os como campos importantes para a qualidade do trabalho dos profissionais da educação, a quem se atribui a responsabilidade de, senão exclusivamente, instituir, promover, garantir e perpetuar um ensino, também, de qualidade. Nesse processo, todavia, não linear e nem causal (boa formação resulta em boas práticas de ensino), muitos outros fatores interagem-se, entrecruzam-se e influenciam um dado trabalho docente para que se possa aferir, por meio de uma avaliação do desempenho, um mérito sobre essa qualidade. Uma das questões candentes desses processos avaliativos que aferem uma dada qualidade do sistema educativo é especificar, conforme esclarece Gatti (2011), de que tipo de qualidade está se falando e quem está decidindo o que compõe essa qualidade.

Para atender a essa lógica de avaliação dos sistemas educativos, vários países da União Europeia (Portugal, Espanha, Reino Unido, Alemanha, França, entre outros) e das Américas definiram a ADD como parâmetro para se aferir a qualidade do trabalho docente, ${ }^{4}$ embora não se esteja ainda 
generalizada no continente americano como uma prática sistemática. Murillo Javier (2007), ao proceder uma análise sobre a organização dos sistemas de carreira e a ADD em 50 países situados na América e Europa, por meio de documentos oficiais emanados pelos Ministérios de Educação, detecta cinco modelos que estão presentes nessa avaliação; são eles:

- evaluación del desempeño docente como parte de la evaluación del centro escolar, con énfasis en la autoevaluación;

- evaluación del desempeño docente para casos especiales, tales como la concesión de licencias;

- evaluación del desempeño docente como insumo para el desarrollo profesional, pero sin ninguna repercusión para la vida profesional del docente;

- la evaluación como base para un incremento salarial;

- la evaluación para la promoción en el escalafón docente.

A partir da análise desses modelos, conclui o autor que:

- es posible un sistema educativo de calidad sin un sistema de evaluación externa del desempeño docente;

- la evaluación del desempeño docente tiene limitaciones, pero no hay consenso sobre lo que es un docente de calidad;

- es necessário contar com un sistema de evaluación del desempeño profesional aceptado por la comunidade educativa y sea impecable tecnicamente (MURILLO JAVIER, 2007, p. 30).

Nessas avaliações, todavia, há algo similar nos respectivos países: o trabalho do professor pode ser avaliado satisfatoriamente ou não na medida em que corresponde (ou se afasta) a um conjunto de padrões de desempenho (perfil profissional) a serem demonstrados objetivamente pelos docentes em sua atividade laboral, predominantemente na atividade de ensino, pois esse passa a ser considerado o aspecto mais importante do desenvolvimento e da aprendizagem dos alunos e da escola, daí porque ter atenção à qualidade do trabalho do professor (e do ensino) tornou-se a mola mestra da ADD em Portugal. 
Se o ensino é entendido como a atividade nuclear e primordial do trabalho docente, os PDD traduzidos em dimensões, domínios, descritores e indicadores a serem alcançados pelos professores são, então, definidos para balizar/ orientar/monitorar o trabalho docente ao longo da carreira. Destaca-se que tais padrões são reveladores de um conjunto de conhecimentos, saberes, competências, capacidades, tarefas e atitudes que o professor deve mobilizar no exercício de sua profissão, constituindo-se, sobretudo, um elemento de referência dos modelos de ADD em diferentes países. Há, portanto, um saber profissional em curso, em que se reconhece o que é ser um professor, ou mesmo o que se espera dele em termos de desempenho profissional. Nessa lógica, a especificidade da profissionalidade docente concretiza-se, nomeadamente, na função de ensinar, visto que a qualidade do sistema educativo é aferida tendo em conta as atividades desenvolvidas por professores (ensino) e alunos (aprendizagem) que efetivamente se restringem à sala de aula.

Outra similaridade a destacar, mesmo com as especificidades que são inerentes a cada país, diz respeito ao fato de que o foco da ADD são as competências (tarefas) a desenvolver e demonstrar na atividade laboral, na tentativa de responder às demandas do processo de reestruturação produtiva instalado também nas escolas, as quais impõem ao docente um novo perfil de funcionário público, cujo desempenho seja cada vez mais eficiente e eficaz. Nesse processo, a relação contratual estabelecida entre os professores e o Estado (seleção, ingresso, carreira, regime de contrato, promoção, progressão, incrementos salariais, reforma, entre outros) vem sendo, em grande medida, condicionada pelas políticas econômicas que incidem sobre o trabalho e a valorização da profissão.

É nesse sentido que carreira profissional e avaliação docente estão fortemente entrelaçadas, principalmente para manter os professores supostamente motivados durante toda sua vida profissional. Murillo Javier (2007) constata que o investimento na revisão da carreira profissional trouxe grandes consequências positivas para a profissão docente: desenvolvimento dos professores ao longo da vida profissional; apoio e melhoramento de seu desempenho; favorecimento de adequadas condições 
de trabalho; oferta de oportunidades de crescimento e satisfação laboral. Contudo, apontam os estudos desenvolvidos pelo autor que em alguns países persistem, ainda, a tendência a entender a carreira como um conjunto de regulações que normalizam administrativamente o ingresso, a promoção e a aposentadoria, cuja avaliação docente atrelada a esta continua associada ao controle e à sanção mais do que ao desenvolvimento profissional e à melhoria das escolas.

Dos estudos internacionais sobre ADD (MURILLO JAVIER, 2007; FLORES, 2010), podemos destacar, então, algumas sínteses similares que julgamos importantes para o desenvolvimento deste artigo:

- uma educação de qualidade conta com docente de qualidade;

- é importante favorecer a melhora constante do desempenho do professor como uma condição para o exercício profissional e para a melhoria da qualidade do ensino;

- é necessário apoiar, valorizar e reconhecer o trabalho docente mediante um sistema que reconheça seu esforço e bom desempenho;

- a carreira docente e a avaliação do desempenho estão fortemente entrelaçados entre si, com outros fatores do sistema educativo e com as decisões relativas à organização da função pública.

A despeito dessas similaridades, Murillo Javier (2007) sublinha que as decisões adotadas em cada país estudado têm sido radicalmente diferentes em seu planejamento e desenvolvimento, de tal forma que é possível afirmar que há mais diferenças do que analogias nos planos de carreiras e de ADD. Dependendo da teoria, dos propósitos, das perspectivas e das consequências da $\mathrm{ADD}$, podemos ter processos avaliativos, conforme esclarece Gatti (2011), que se diferenciam: uns que se aproximam mais para uma natureza educativa (implica perspectivas de consenso, diálogo, troca; carrega a ideia de melhoria, de contribuição ao desenvolvimento pessoal e profissional), outros de natureza seletiva (ideia de seletividade e ranqueamento, de punição e negatividade), outros, ainda, 
5 Adverte Gatti (2011) que é muito simplista a noção de que [...] um resultado numa escala avaliativa será suficiente para melhorar ou modificar conceitos e práticas ligadas ao trabalho profissional de professores. [...] é simplista, ainda, a concepção que resultados divulgados de avaliações diversas de redes por si, provoquem mudanças reais. Acrescenta a autora que as avaliações que têm por objetivo criar condições de mudanças conceituais, de atitudes e práticas, precisam ganhar sentido no meio socioeducacional no qual as pessoas, os profissionais, que serão abrangidos por elas, vivem Ou seja, sem ter sentidos para esses, as avaliações caem num vazio, não mobilizam e não geram consequências positivas. que tentam conjugar essas duas polaridades em um mesmo processo, por vezes não conseguida.

É suposto, todavia, que a ADD deva ser conceitualmente sólida, bem planejada e implementada. Precisa ser equitativa, transparente, negociada, justa, ética para que a sua qualidade técnica e política seja indiscutível e confiável pelos avaliados. Essa perspectiva de avaliação pode estar mais associada à avaliação formativa quando é processual, pedagógica, põe em evidência o contexto e objetiva a melhorar ou assegurar a qualidade do trabalho docente e a favorecer o desenvolvimento profissional e pessoal contínuo. Subentende-se que são práticas avaliativas que contribuem para que os professores reflitam sobre as suas práticas, aprendam com elas, tendo em vista melhorá-las, superem problemas e alavanquem mudanças de concepções, atitudes, conhecimentos e práticas no interior das escolas. ${ }^{5}$

A ADD, entretanto, pode ancorar-se em uma avaliação somativa quando o que importa é, na perspectiva de prestação de contas, obter informações sobre a produtividade do trabalho docente para tomar alguma decisão, muitas vezes burocrática, a respeito desse profissional, como progressão na carreira, incremento salarial, atribuição de prêmios de desempenho, sanções, punições, demissões, entre outros. Combinar esses dois propósitos na ADD em um mesmo processo tem sido um dos grandes desafios dos países para a melhoria do sistema educativo, entre eles, o de Portugal, pois, para além do seu planejamento e desenvolvimento, tal avaliação, como analisa Gatti (2011), cria representações e gera consequências e efeitos nem sempre favoráveis.

Gatti (2011) reflete, em seus estudos, que a avaliação de professores é um campo complexo. Posada (2009), por sua vez, argumenta que avaliar o trabalho de qualquer profissional não é tarefa fácil, ainda mais se esse trabalho estiver dependente da sua natureza e das incertezas de seus processos e resultados, como é o campo educacional. Nessa perspectiva, adverte o autor, a avaliação dos profissionais da educação é extremamente difícil por várias razões, dentre as quais destaca: a incerteza do trabalho, processualidade do trabalho e a multidimensionalidade da ação educativa, o 
que torna imponderável uma avaliação realista dos respectivos profissionais.

Nesse sentido, a fixação de padrões de desempenho, a definição de competências, objetivos e metas que serão exigidos para o eficiente e eficaz trabalho tornam-se fulcral para que um sistema avaliativo tenha elementos mensuráveis e claros, portanto confiáveis para se aferir um mérito acerca da execução das tarefas desempenhadas pelo trabalhador. É nessa perspectiva que, a seguir, centrar-me-ei em uma discussão sobre os PDD, visto ser um meio formal importante para a avaliação docente em Portugal.

\section{PADRÕES DE DESEMPENHO DOCENTE EM PORTUGAL: CONTROLE E MONITORAMENTO DO TRABALHO DOS PROFESSORES}

De Ketele (2010) defende a tese de que os processos de ADD devem ser orientados por uma postura de reconhecimento em vez de uma postura de controle, visto que esta tem como consequência mais efeitos perversos do que efeitos positivos sobre a qualidade do ensino de um docente e do seu desenvolvimento profissional. Para esse autor, uma postura de controle é essencialmente um dispositivo top-down: é essencialmente da responsabilidade das autoridades que têm como obrigação prescrever o desenvolvimento profissional, proporcionar as condições necessárias e fazer uma avaliação pelos seus superiores hierárquicos, por meio de um exame do grau de conformidade entre o prescrito e o realizado pelos professores.

Com base nessa perspectiva tomemos a seguinte questão para reflexão: qual a finalidade dos padrões de desempenho docente adotados em Portugal? Quais as suas implicações para o trabalho de professores?

A avaliação de desempenho na administração pública tem sido tomada pelos governos como um instrumento importante de gestão da coisa pública em todos os setores no sentido de se estabelecer uma cultura de excelência e de qualidade nas instituições cujos serviços, trabalhadores e dirigentes possam ser, cada vez mais, eficientes e eficazes 
evitando-se com isso o desperdício do erário público e a ineficácia da gestão, como destaca Moura (2012).

Com a crise do Estado do Bem-Estar Social em Portugal e a crença de que ele transformou o aparelho estatal em uma máquina pesada, cara e burocrática, torna-se preciso modernizar a função pública em uma lógica de governança econômica, razão pela qual se associa o valor da remuneração dos trabalhadores à sua produtividade, não mais à sua formação e ao tempo de serviço. Com base nessa lógica, entre outras, justifica-se a criação, pela primeira vez em Portugal, de um sistema de avaliação de desempenho na administração pública, considerado por Moura (2012) como adequado, idôneo, exigente, efetivo e rigoroso.

Ao objetivar a melhoria de desempenho dos trabalhadores e dirigentes e de qualidade de serviços prestados na administração pública, Portugal, por meio da Lei n. 66-B/2007, de 28 de dezembro, estabelece o Sistema Integrado de Gestão e Avaliação do Desempenho na Administração Pública (Siadap). Gestão e avaliação, então, tornam-se instrumentos indissociáveis para o alcance de tal objetivo, pois é por meio da gestão (gestão do desempenho) que se define com precisão a natureza do trabalho (planejamento, organização, local, desempenhos, competências, tarefas e objetivos a cumprir), o que é esperado pelo trabalhador em termos de competências e habilidades (perfil dos postos de trabalho), os resultados a atingir (produtividade), entre outros.

Nesse contexto, é por intermédio da avaliação do desempenho (gestão da avaliação) que se atribui um mérito ao desempenho dos trabalhadores e dirigentes com base no cumprimento de objetivos e metas, cujos resultados alcançados permitem identificar o grau de sua produtividade em um determinado período temporal, bem como a qualidade dos serviços públicos que a instituição oferece. A definição de metas e objetivos a serem alcançados pelos trabalhadores da administração pública portuguesa é justificada pelo ente público como forma de se ter parâmetros de eficiência e eficácia, distinguindo-se pelo mérito aqueles que os alcançam dos que não logram alcançar, pois a ideia de que todos devam ser tratados da mesma forma, independente de sua 
produtividade, é algo socialmente inaceitável e inconstitucional na sociedade portuguesa, como justifica Moura (2012).

A eficiência e eficácia da gestão por objetivos impõem, deste modo, uma condição incontornável ao trabalhador público tendo em vista a cultura do mérito: para aqueles que alcançam a totalidade dos objetivos e metas resta-lhes procurar sistematicamente a superação dos resultados já alcançados. Assim, a avaliação por desempenho induz o trabalhador à incessante procura da excelência, ao buscar, sempre e incansavelmente, ultrapassar seus objetivos e melhorar sua performance, pois sempre há algo em que se melhorar em uma lógica de trabalho competitiva e concorrencial. Nessa ótica, pressupõe-se evitar a estagnação, a desmotivação e o imobilismo do trabalhador, ou seja, a ineficácia dos serviços. Não é de se estranhar, então, que essa gestão é concebida como de responsabilização individual, coletiva e institucional, pelo que se permite (co)responsabilizar o trabalhador pelo sucesso ou insucesso dos resultados alcançados, uma vez que, como pondera Moura (2012), o emprego de fundos públicos não mais permite que não haja responsabilidade de todos os intervenientes pelos resultados.

O Siadap configura-se, então, como um sistema de avaliação de desempenho e, como tal, expressa um conjunto de determinações avaliativas, pelas quais o avaliador possa aferir, medir, classificar o mérito e a produtividade dos serviços, dirigentes e trabalhadores públicos. Se o fim imediato e primordial (MOURA, 2012) é a eficácia e a eficiência dos serviços públicos ao maximizar o grau de satisfação das necessidades dos utilizadores mediante a minimização dos meios despendidos (relação custo/benefício), o meio para que esse fim seja alcançado traduz-se pela efetivação de um rigoroso sistema padronizado de avaliação de desempenho, pois, acrescenta o referido autor, comportamentos desviantes ou improdutivos têm repercussões sobre a eficiência dos serviços e devem ser corrigidos, ou mesmo, sancionados.

Sendo o objetivo primordial do Siadap melhorar a gestão, o desempenho e a qualidade em função dos objetivos das políticas públicas e da relação custo-benefício numa lógica de produzir mais e melhor com menor custo, tendo em vista a crise econômica que acomete Portugal, todo o serviço público 
teve que rever suas políticas avaliativas, adequando-as às suas normas. Dentre essas normas, a do setor educacional, razão pela qual a avaliação docente tem sido um dos grandes desafios do Estado, quer seja pelos processos instaurados até então terem recebido profundas reações e resistências por parte dos professores, quer seja pelas suas consequências em que estão em jogo progressão na carreira, melhoria salarial, prestígio e desenvolvimento pessoal e profissional.

Os Padrões de Desempenho Docente em Portugal (PDD) foram estabelecidos por meio do Despacho n. 16034/2010, em 22 de outubro. Nesse Despacho, a associação entre ADD e PDD fica explícita quando o legislador sublinha que esse aparato normativo é um documento orientador para a afirmação de um dispositivo de avaliação que se deseja justo, confiável e que contribua efetivamente para o desenvolvimento profissional dos professores. Ressalto que o foco da atual política de ADD, estabelecida pelo Decreto Regulamentar n. 26/2012, centra-se na qualidade do trabalho dos docentes, a quem cabe assegurar um ensino com melhor produtividade e resultado, daí a sua função principal de ensinar e promover a aprendizagem dos alunos. Trabalho esse que deve corresponder a um conjunto de padrões de desempenho a ser demonstrado pelos professores em sua atividade laboral.

Tais padrões foram definidos no âmbito nacional com o intuito de contribuir para a orientação do trabalho docente; para possibilitar a autorreflexão dos professores e, especialmente, para articular a avaliação de seu desempenho assentada fundamentalmente no grau de concretização de objetivos e metas, sendo determinante para renovação de contratos; nomeações; progressão e promoção na carreira; atribuição de prêmios de produtividade/desempenho; melhoria salarial; gozo de período sabático; estágios e ações de formação; acréscimo de dias no período de férias, entre outros. Esses padrões definem as "características fundamentais da profissão docente e as tarefas profissionais que dela decorrem, caracterizando a natureza, os saberes e os requisitos da profissão" (PORTUGAL, 2010), por isso eles são considerados pelo legislador como um elemento de referência e orientador da $\mathrm{ADD}$, os quais, presumidamente, permitam (re) orientar a prática docente. Assim, ao se definir PDD 
nacionalmente, o referido documento expressa o que se espera do professor em termos de atribuições e desempenhos profissionais ao elencar um conjunto de tarefas as quais serão checadas se foram ou não realizadas pelos docentes quando avaliados.

Com efeito, a avaliação da performance dos professores surge como um importante instrumento de controle e monitoramento de suas práticas, que passam a ser orientadas mais pelos resultados e produtividade que alcançam. É por meio dela que se obtém a informação se o docente pode ser considerado ou não eficiente e eficaz na medida em que o grau de concretização dos objetivos alcançado possa explicitar de maneira inequívoca a demonstração das competências, visto que é nesse confronto que se distinguirá o mérito (desempenho) dos avaliados. Quanto mais próximos ao padrão desejável, e superá-lo, mais eficiente será considerado esse professor, contudo as consequências dessa avaliação podem ter efeitos positivos (premiação/bonificação/assegurar direito trabalhistas) ou negativos (penalização/sanções/mal-estar). É nessa distinção (efeitos positivos/negativos) que reside um dos grandes dilemas do professorado público português, pois se os resultados alcançados pelos docentes não forem satisfatórios a ameaça se instaura, como preconiza Moura (2012), ao afirmar que se torna "insustentável em qualquer administração pública moderna continuar a assegurar o mesmo tratamento a todos os trabalhadores públicos, independentemente do seu rendimento e atitude perante o serviço.

Destaca-se que o legislador preocupado com uma provável interpretação equivocada das escolas e dos professores portugueses sobre as normas do PDD ou mesmo pelo não cumprimento das mesmas adverte, de antemão, que tais padrões "devem ser lidos em contexto, de acordo com o projeto e característica de cada escola e com as especificidades da comunidade em que se insere" (PORTUGAL, 2010), recomendação, ao que tudo indica, pelas reações dos docentes à ADD em causa, sem efeito prático.

Avaliar o trabalho de professores é complexo e difícil, como já referido anteriormente, pois há nesse processo uma cultura docente, um ethos profissional, em que o saber e a prática profissional são (re)construídos em contexto mediante 
6 Constituem as vertentes caracterizadoras da atuação profissional do docente, estruturantes do perfil profissional desejado.

7 Os domínios operacionalizam as dimensões em planos mais restritos permitindo descrever de forma clara os aspectos do desempenho docente e os correspondentes deveres e responsabilidades profissionais

8 Traduzem a operacionalização do desempenho docente em evidências nos domínios, contribuindo para orientar a ação profissional.

9 A definição de níveis de desempenho tem por objetivo a descrição pormenorizada do desempenho docente por forma a clarificar o que deve ser avaliado.

A formulação dos níveis descreve comportamentos passíveis de serem observados ou documentados e de acordo com uma escala que determina o seu grau de concretização.

10 São cinco níveis de avaliação de desempenho docente: excelente muito bom, bom, regular e insuficiente. a forma como o professor se vê, é reconhecido e valorizado pela sociedade, pelo Estado e pela escola, e como se relaciona com o seu próprio trabalho, o que gera diferentes e, por vezes, antagônicos valores: concepções e práticas de educação, docência, ensino, aprendizagem, avaliação. É nesse sentido que as reflexões de Gatti (2011) nos ajudam a compreender que a ADD de natureza educativa pressupõe colocar em evidência: a) as realidades locais específicas para o exercício da docência; b) a formação dos docentes e avaliadores; c) a cultura regional/ local, ao que nos parece, o terreno onde deve assentar-se tal avaliação em uma perspectiva formativa.

Na força da lei, os padrões de desempenhos são entendidos como o desempenho eficiente e eficaz que é exigido do trabalhador pelo Estado, tendo em vista a melhoria do funcionamento dos serviços prestados em razão das necessidades dos seus clientes e do próprio Estado, cujo fim desejado é o de fazer mais e melhor com menos, com um custo reduzido ou com um menor custo possível, uma vez que, como diz Moura (2012), as sociedades contemporâneas não se compadecem com o "esbanjamento" de recursos coletivos.

Para o corpo do professorado, tais padrões foram organizados inicialmente em 4 dimensões ${ }^{6}$ desdobradas em domínios, ${ }^{7}$ decompostos em indicadores, ${ }^{8}$ que, por sua vez, são pormenorizadas em um conjunto de descritores ${ }^{9}$ para cada nível ${ }^{10}$ em que se busca atribuir o mérito dos professores e distingui-los com base em evidências explicitamente demonstráveis. Medir e diferenciar o desempenho dos professores constituiu-se, em Portugal, no principal objetivo a alcançar por meio de uma avaliação de natureza seletiva, contestada de forma contundente pelos docentes (COUTO, 2010; NUNES, 2011; NUNES; RODRIGUES, 2011; SANTOS, 2012).

Foram, então, definidas quatro dimensões que constituem as vertentes caracterizadoras da atuação profissional docente, as quais, como recomenda o dispositivo, devem ser trabalhadas articuladas e integradas: 1) vertente profissional, social e ética; 2) desenvolvimento do ensino e da aprendizagem; 3) participação na escola e relação com a comunidade educativa; 4) desenvolvimento e formação profissional ao longo da 
vida. Elas foram definidas com esses teores porque, segundo a ótica do legislador, consagram conceitos essenciais sobre o que representa integrar a profissão docente e identificam conhecimentos, capacidades e atitudes que esse professor deve demonstrar, estabelecendo-se, assim, um conhecimento profissional ${ }^{11}$ indispensável à construção de um dado perfil de trabalhador. Conhecimento esse que precisa ser, ao longo da carreira, permanentemente reconstruído e avaliado.

Essas dimensões, contudo, não têm o mesmo peso e importância para o trabalho e $\mathrm{ADD}$, visto que o legislador deixa claro que a segunda dimensão deverá ocupar um lugar central na escola, pois a função principal desse profissional é ensinar e promover a aprendizagem dos alunos, sendo as demais complementares a ela. O que se deduz que o ensino (concepção, planejamento, operacionalização e regulação do ensino e da aprendizagem) constitui o cerne da atividade docente e a missão central da escola porque dele resulta uma dada qualidade da aprendizagem dos estudantes a ser medida, sobretudo, em avaliações nacionais e internacionais. Acrescenta o diploma que as demais dimensões não podem ser olhadas isoladamente, as quais devem refletir-se no ensino realizado, na qualidade das aprendizagens e na formação dos alunos.

Os PDD, recomendados pelo legislador para serem vistos de forma integrada e global, apresentam e descrevem separadamente cada dimensão e domínio que se espera desse desempenho. Veremos agora o que se espera para cada dimensão.

A dimensão vertente profissional, social e ética, de responsabilidade individual do professor, representa em seu conjunto um código deontológico onde são firmados os compromissos que esse profissional deve honrar: compromisso com a construção e o uso do conhecimento profissional; compromisso com a promoção da aprendizagem do desenvolvimento pessoal e cívico dos estudantes e compromisso com o grupo de pares e com a escola. Sendo um acordo formal entre partes, o docente compromete-se com a sua profissão, alunos, pares e escola a realizar um trabalho que favoreça, em última instância, a qualidade do ensino e da escola. Em seus indicadores, expressões como: reconhecimento, reflexão, atitude e responsabilização são destacadas
11 Entendido como o conjunto articulado de elementos necessários ao desempenho da ação, que envolve saberes e competências no âmbito do currículo e da didática, dos conteúdos, dos processos de ensino e da sua adequação aos diferentes contextos e necessidades dos alunos. 
como forma de chamar a atenção dos professores de que é necessário ele reconhecer a importância de se estar em permanente estado de reflexão sobre o seu trabalho, o que demonstraria uma atitude pró-ativa e de responsabilização pelo seu desenvolvimento profissional e pelo projeto educativo da escola. A dimensão ética é requisitada quando o docente deve "empenhar a palavra e comprometer-se a realizar algo", questões que na ótica dos professores portugueses não são tão objetivas a desenvolver, demonstrar e a avaliar, como analisa Nunes (2011). Por essa dimensão estar relacionada a questões de valores, atitudes e ao desempenho profissional do docente face à profissão, ela é considerada transversal, devendo abarcar as outras três dimensões. Tal dimensão busca dar vazão ao conhecimento profissional que o professor já traz e (re)constrói ao longo da carreira.

A dimensão desenvolvimento do ensino e da aprendizagem é compreendida como o eixo central da profissão, do trabalho a desenvolver e da avaliação do desempenho docente, daí porque o planejamento, operacionalização, regulação do ensino e das aprendizagens dos alunos constituem-se em tarefas fundamentais do docente. Nessa perspectiva, o conhecimento científico e pedagógico-didático do professor ganha destaque para subsidiar com rigorosidade, profundidade e eficácia tais tarefas, especialmente a da transmissão dos conteúdos de ensino, considerada pelo Estado como o elemento essencial do currículo, pois é por meio da apropriação dele pelos alunos (aprendizagens) que os mesmos serão avaliados.

Logo, não é qualquer conteúdo que interessa. A seleção e escolha dele devem ter como princípio a objetividade, ou seja, centrado em aspectos fundamentais daquilo que se julga como "conhecimento essencial" que precisa ser ensinado aos alunos ao longo das várias etapas de escolaridade, conforme orienta o Despacho n. 17169/2011 (PORTUGAL, 2011). A compreensão de "não se desviar a atenção" e, por conseguinte, focar no ensino dos conteúdos estritamente necessários e fundamentais para evitar o desperdício de tempo e de conteúdos desnecessários tem uma lógica para a ADD, pois implica uma organização e ministração do ensino mais objetiva, mais passível de controle e disciplina ao se prever o que se pretende 
alcançar de forma mais clara e ordenada, permitindo que professores e alunos concentrem-se no que é essencial, o que, em última instância, implica uma avaliação mais objetiva sobre o resultado do trabalho do docente e o do desenvolvido pela escola, ambas as avaliações podendo ser realizadas primordialmente por intermédio da avaliação dos conhecimentos adquiridos pelos estudantes (PORTUGAL, 2011).

A ênfase da avaliação nessa dimensão está umbilicalmente ligada à concepção de que, por meio de um processo de ensino planejado, organizado, trabalhado com rigor, eficiência e eficácia, os alunos supostamente desenvolveriam suas aprendizagens com mérito, alcançando sucesso em seus resultados avaliativos decorrentes de exames nacionais e internacionais. Tal assertiva encontra amparo, entre outros, nos argumentos do Ministério da Educação e Ciência, presentes no documento que dá amparo legal à revisão do currículo nacional que tem como objetivo central "elevar os padrões de desempenho dos alunos em Portugal" (PORTUGAL, 2012a), tendo em vista atender às prioridades estabelecidas no Programa do XIX Governo Constitucional ${ }^{12}$ para o setor da educação. Assim, mediante essa dimensão, espera-se dos professores uma participação ativa para a construção de uma escola eficaz cujo ensino seja o elemento decisivo para a qualidade da aprendizagem dos alunos.

A participação na escola e a relação com a comunidade educativa é uma outra dimensão em que o professor é visto como corresponsável pelo trabalho pedagógico da escola como um todo, cujas tarefas de gestão, supervisão, coordenação, avaliação, investigação e inovação se juntam às de ensinar. Sua função deve contribuir para dar visibilidade ao serviço que a escola oferece, assumindo um papel ativo na relação desta com a comunidade, aproximando-as. A quarta dimensão, desenvolvimento e formação profissional ao longo da vida, conhecimento específico e reconstrução do conhecimento profissional, dedica-se a perceber o grau de envolvimento dos docentes no que se refere ao investimento em seu processo de desenvolvimento profissional e pessoal.

Os domínios ${ }^{13}$ por dimensões podem ser visualizados pelo seguinte quadro:

12 Primeiro-Ministro Pedro Passos Coelho, empossado em 21 de junho de 2011.

13 Com a promulgação do Decreto-Lei n. 41/2012, em 21 de fevereiro, a ADD passa a ser incidida sobre três grandes dimensões, somente: a) a científico-pedagógica, que se destaca pela sua centralidade no exercício profissional; b) a participação na vida da escola e na relação com a comunidade educativa e c) a formação contínua e o desenvolvimento profissional, que de forma transversal, destaca o referido Decreto, são indissociáveis dos pressupostos deontológicos que enquadram a vertente profissional, social e ética do trabalho docente. 
QUADRO 1: Domínios e dimensões da Avaliação do Desempenho Docente

\begin{tabular}{|c|c|}
\hline DIMENSÕES & DOMÍNIOS \\
\hline 1. Vertente profissional, social e ética & $\begin{array}{l}\text { Compromisso com a construção e uso do conhecimento profissional. } \\
\text { Compromisso com a promoção da aprendizagem e do desenvolvimento } \\
\text { pessoal e cívico dos alunos. } \\
\text { Compromisso com o grupo de pares e com a escola. }\end{array}$ \\
\hline $\begin{array}{l}\text { 2. Desenvolvimento do ensino e da } \\
\text { aprendizagem }\end{array}$ & $\begin{array}{l}\text { 2.1 Preparação e organização das actividades lectivas. } \\
\text { 2.2 Realização das atividades letivas. } \\
\text { 2.3 Relação pedagógica com os alunos. } \\
\text { 2.4 Processo de avaliação das aprendizagens dos alunos. }\end{array}$ \\
\hline $\begin{array}{l}\text { 3. Participação na escola e relação com a } \\
\text { comunidade educativa }\end{array}$ & $\begin{array}{l}\text { 3.1 Contributo para a realização dos objectivos e metas do Projeto Educativo } \\
\text { e dos Planos Anual e Plurianual de Actividades. } \\
\text { 3.2 Participação nas estruturas de coordenação educativa e supervisão } \\
\text { pedagógica e nos órgãos de administração e gestão. } \\
\text { 3.3 Dinamização de projectos de investigação, desenvolvimento e inovação } \\
\text { educativa e sua correspondente avaliação. }\end{array}$ \\
\hline $\begin{array}{l}\text { 4. Desenvolvimento e formação } \\
\text { profissional ao longo da vida }\end{array}$ & 4.1 Formação contínua e desenvolvimento profissional. \\
\hline
\end{tabular}

Fonte: Portugal (2010).

Para cada dimensão e seus domínios um conjunto de indicadores foram pensados, para os quais foram definidos um elenco de cinco níveis em que se atribui o mérito do desempenho docente (excelente, muito bom, bom, regular e insuficiente) em uma escala que determina o grau de concretização dos descritores (tarefas realizadas ou não). A apreciação final deve resultar da articulação dos vários desempenhos descritos em cada domínio, bem como da relação entre as quatro dimensões.

Quanto mais próximo estiver o docente ao grau superior ("excelente" ou "muito bom") mais ele se situa no patamar de desempenho de níveis mais elevados, situação em que se reconhece a sua influência e o papel de referência dele na escola e na profissão. Os que transitam em níveis de "regular" e "insuficiente" correspondem a desempenhos com limitações ou grave limitações, e os que se situam em níveis "bom" demonstram um desempenho que corresponde ao enunciado dos descritores sem limitações. De qualquer forma, são níveis que objetivam diferenciar e destacar os melhores profissionais daqueles que, porventura, precisam de supervisão e monitorização, tendo em vista a melhoria de sua prática pedagógica. Nessa lógica, distinguir o mérito, para muitos, é uma forma de contribuir para a valorização do trabalho e da profissão docente, contudo há de se perguntar se tal perspectiva alimenta um processo de trabalho em 
que a produtividade, competitividade e concorrência são estimuladas como elementos diferenciais do trabalho docente.

É neste cenário que os descritores anunciam objetivamente os comportamentos passíveis de serem demonstrados pelos professores e observados ou documentados pelo avaliador no sentido de objetivar a apreciação do desempenho, tornando a avaliação supostamente mais fiável, credível, inequívoca e incontestável. Assim, é visível que qualquer apreciação seja orientada por critérios objetivos de avaliação de desempenho, ou seja, a objetividade deve basear-se em indicadores mensuráveis comprovados empiricamente, cujo grau de concretização nada pode ter de subjetivo visto que tal procedimento é uma forma de garantir que a avaliação não correrá o risco de ser questionada, levantando-se suspeita sobre a idoneidade dos avaliadores e dos resultados alcançados (MOURA, 2012). Lembrando Couto (2010), Moreira (2011), Nunes (2011) e Santos (2012), tais descritores acabaram por ser tornar, na maioria das escolas, uma bateria/lista de aspectos e tarefas infindáveis a serem desenvolvidos pelos professores constituindo-se em mais um elemento de controle, regulação e monitoração do trabalho docente, na medida em que definem o que constituirá a natureza desse trabalho e disciplinam os eventuais desvios a ele.

Medir performances de professores sem considerar suas histórias, contextos e situação de profissionalidade não é tarefa fácil! Daí porque os PDD de referência nacional (perfis profissionais) precisam ser vistos, correspondidos e avaliados com cautela devido a sua subjetividade e complexidade. Deles se depreende que há um conjunto de obrigações relativas à conduta do professor que tende a regular o trabalho docente na sua universalidade. Produz-se, assim, um discurso único sobre o exercício da profissão docente quando se formata um possível padrão de desempenho que o professor se vê obrigado a corresponder tendo em vista a avaliação de sua prática pedagógica.

Fica patente na análise dos PDD em Portugal que está em jogo um dado perfil profissional nacional que precisa ser garantido uniformemente pelo governo, tendo em vista responder a complexidade do processo ensino aprendizagem 
cada vez mais distante de melhores resultados. A padronização do trabalho docente é então concebida como uma forma de evitar o trabalho desnecessário, desperdício de esforço e de energia, numa lógica em que nada pode fazer com que os professores se distraiam e, logo, se distanciem das metas estabelecidas pelo próprio e pelas escolas no alcance de melhores resultados.

Nesses perfis são incorporadas exigências laborais que vão para além do conhecimento e destrezas inerentes ao ato de ensinar (componente letivo), mas também incluemse parâmetros que dizem respeito a gestão, investigação, supervisão, inspeção e avaliação (componentes não letivos), alargados, ainda, com outras destrezas que revelem atitudes e compromissos, atribuindo maior responsabilização aos professores frente à mudança dos indicadores de qualidade, razão pela qual "un buen docente no es aquel que sabe su materia y sabe enseñarla, es, fundamentalmente, un profesional comprometido con su labor y su mejora" (MURILLO JAVIER, 2007, p. 31).

Para caracterizar de forma mais clara a atividade laboral do professor e ter-se parâmetros mais visíveis para proceder uma dada ADD, as atividades profissionais dos docentes em Portugal são desenvolvidas em uma jornada de trabalho de 35 horas semanais de serviço, distribuídas em atividades de componentes letivo e não letivo. As atividades relacionadas ao primeiro componente, muito valorizada pela ADD, variam conforme o nível de ensino em que atuam os professores: 25 horas para os docentes da educação infantil e do $1^{\circ}$ ciclo ( $1^{\circ}$ ao $4^{\circ}$ ano do ensino básico) e 22 horas para os demais professores ( $2^{\circ}$ e $3^{\circ}$ ciclos e ensino secundário), que podem ser reduzidas em até no máximo 8 horas dependendo do tempo de serviço. O que resta nessa contabilidade da carga horária de trabalho do professor destina-se às atividades não letivas, subvalorizadas para efeitos de ADD.

É, portanto, na distribuição dos serviços em atividades letivas e não letivas que o professor desenvolve seu trabalho e que por ele será avaliado, tendo como instrumento de registro das informações obtidas as grelhas. Portanto, estas, como instrumentos avaliativos, são uma fonte de comprovação dos 
resultados efetivamente alcançados, permitindo, objetivamente, o confronto de desempenhos entre os avaliados. $\mathrm{Na}$ prática, tais padrões de desempenho ganharam visibilidade em inúmeras grelhas e subgrelhas altamente pormenorizadas, com os mais diferentes descritores, tornando-se uma parafernália avaliativa, um procedimento meramente burocrático que tinha que ser preenchido sem qualquer significado e conteúdo aos professores, como nos informam Couto (2010), Moreira (2011) e Santos (2012). Ademais, ressalta Couto (2010) que as escolas tiveram grandes dificuldades em definir claramente objetivos e padrões de desempenho profissional, bem como em construir instrumentos adequados de recolha de informação, agravando o clima de mal-estar entre os professores, entre avaliadores e avaliados em função do modelo de $\mathrm{ADD}$ posto em vigor.

Destaca-se que, na maioria das grelhas avaliativas de ADD, formuladas pelas escolas portuguesas, o componente letivo abrange um trabalho que diz respeito à tarefa de ensinar propriamente dita, restrita ao ambiente de sala de aula e desempenhada por meio de uma relação pedagógica exclusivamente com os alunos, ou seja, tal tarefa é contabilizada pelo número de horas lecionadas em uma dada disciplina. Esse componente, por ter maior carga horária destinada a ele e ter maior extensão e peso no processo de trabalho do professor e no de ADD, é uma tentativa do governo e das escolas portuguesas em pôr o ensino como centralidade pedagógica e, consequentemente, avaliativa. O que está em causa nessa lógica é o fato de os professores e os estabelecimentos de ensino focarem-se naquilo que julgam ser o essencial de seu trabalho: o ensino, pois é por meio da avaliação dele e de quem o ministra que é possível a melhoria dos resultados escolares. Ora, se o foco da ADD é o ensino, há consequências previsíveis para o trabalho docente.

O componente não letivo abrange a realização de trabalho de cunho individual (planejamento, organização e preparação de aulas; avaliação do processo ensino-aprendizagem; estudos, etc.) e de tarefas a serem desempenhadas sob a solicitação e coordenação da escola, podendo compreender atividades diversas como, por exemplo: aquelas relacionadas 
ao desenvolvimento curricular; atendimento, acompanhamento e supervisão de alunos, pais e comunidade escolar; enriquecimento cultural; participação em reuniões, conselhos/colegiados, ações de formação continuada; realização de estudos e investigação; assessoria técnico-pedagógica; acompanhamento, apoio e tutoria aos demais docentes; coordenação pedagógica; produção de material pedagógico e de inovação, entre outros.

A multiplicidade de tarefas que agora aos professores são exigidos implica, para efeito de ADD, construção por parte das escolas em inúmeras grelhas avaliativas em que o trabalho docente aparece demasiadamente pormenorizado, parcelado e fragmentado. Ou seja, para obterem melhores classificações e menções avaliativas que correspondam aos padrões de excelência os professores precisam desmultiplicar-se por pequenas atividades parcelares e rotativas; fragmentar e priorizar o seu tempo de trabalho itinerante; permanentemente saltitar de tarefa para tarefa em um tempo intenso e extenso de trabalho, muito dele gasto para além do ambiente escolar, constituindo-se em um problema para os professores, cuja queixa revela-se pela pouca oportunidade para refletir, debater e inovar com seus pares acerca do trabalho pedagógico desenvolvido por eles e pela escola, como constataram Couto (2010), Moreira (2011), Santos (2012).

Vieira e Moreira (2011), entre outros autores, analisam que o trabalho docente português na atualidade caracteriza-se frequentemente pela procura de soluções rápidas para problemas técnicos, sacrificando a reflexão e a procura de respostas políticas e éticas para os problemas complexos da profissão. Sugerem as autoras que é necessário, no espaço escolar, lutar contra a burocratização crescente e asfixiante do trabalho docente bem como contra a falta de um tempo público, como compreende Giroux (2007), em que se possam travar discussões na esfera pública que privilegiem o trabalho colaborativo e os valores democráticos.

Nessa condicionalidade os professores tentam manter-se empregados, satisfeitos e motivados pelo menos por algum tempo, considerando a precariedade do trabalho escolar, cujos estudos de Sampaio e Marim (2004) e Dalila (2004) nos 
ajudam a compreender a sua gênese e consequências em um contexto de mundialização do capital. No entanto, é compreensível, também, a atitude de professores quando, ao se verem ameaçados pela $A D D$, e para se sentirem protegidos dos efeitos da avaliação a que estão a sujeitar-se, ocultam dilemas, tensões, conflitos, problemas e insucessos (VIEIRA; MOREIRA, 2011), demonstrando com essa atitude terem clara noção das relações hierárquicas e de poder que estão presentes no jogo avaliativo que em nada contribuem para o desenvolvimento pessoal e profissional.

Verificamos, ademais, na análise de tais grelhas, a possibilidade de penalizar os docentes no momento em que seu trabalho, ao ser avaliado, não corresponder aos PDD, seja porque determinadas atividades não foram atribuídas a eles ou mesmo porque elas são inadequadas ou inacessíveis ao docente devido, por exemplo, à sua formação ou ao escalão ${ }^{14}$ em que se encontra. Vieira e Moreira (2011) refletem acerca das principais consequências da ADD para os professores:

14 A carreira docente em Portugal possui 10 escalões, os quais correspondem a índices remuneratórios diferenciados.

[...] fortalece as hierarquias e as relações de poder; sujeita o indivíduo a uma grelha geral de competências que faz dele uma entidade comparável, homogeneizada por padrões que valem para todos, ou seja, neutraliza a singularidade; legitima, através desses padrões, o grau máximo de saber e de poder, gerando no indivíduo sentimentos de inferioridade e de impoder face ao avaliador e à imagem ideal do avaliado, favorecendo, desse modo, lógicas de exclusão e autocondenação. (VIEIRA; MOREIRA, 2011, p. 35)

A ADD em análise, em regra, tem seu foco em uma questão central: verificar se o professor demonstra ter capacidades, competências e conhecimentos reclamados pelo seu posto de trabalho. A demonstração de comportamentos, indispensável ao correto, eficaz e eficiente desempenho da função docente, é medida, nessas circunstâncias, pelo grau de concretização dos objetivos alcançados e, sobretudo, ultrapassados. Desse modo, os PDD, ao se basearem em indicadores de medida, permitem diferenciar méritos, distinguir desempenhos e graduar os resultados alcançados pelos professores em termos de não cumprimento, cumprimento ou 
superação dos objetivos propostos, o que tornaria o trabalho docente, cada vez mais, disciplinado, regulado, monitorado, supervisionado tendo em vista maximinizar sua produtividade. Não é sem razão que a linguagem dos PDD presente nos documentos oficiais é reveladora de que a ADD teria um grande contributo ao sistema de ensino como instrumento para alavancar a qualidade do desempenho dos professores, dos alunos, das escolas e do sistema de ensino português.

\section{CONCLUSÃO}

Todo processo avaliativo tem consequências, causa impactos, quer positivos ou negativos para aqueles que são avaliados. No caso da avaliação do desempenho docente, seus resultados, se insatisfatórios na ótica dos avaliados, podem trazer repercussões "duras" para a vida profissional, na medida em que seu saber, competência e prestígio estão em xeque, sofrimento que pode incidir sobre seu trabalho, autoestima e produtividade.

Podemos afirmar, tendo como referência a questão central orientadora deste artigo, que os PDD em curso em Portugal revelam aquilo que o sistema de ensino oficial mais valoriza em termos de perfil profissional e tornam mais exigentes o desempenho e refinamento profissional, visto que obriga os professores a desenvolverem melhor novas e antigas tarefas, responsabilizando-os de forma mais contundente acerca do seu desenvolvimento profissional, qualidade do trabalho e do processo de ensino-aprendizagem e, em última instância, a serem recompensados por isso (menções, méritos, progressão na carreira, incremento salarial, entre outros). Com efeito, os PDD podem ser entendidos como indicadores de avaliação, os quais pressionam os docentes a um desempenho profissional de excelência, portanto mais produtivo em termos de alcance de resultados, quiçá em menos tempo e com menos recursos. Tal pressão é consequência de uma nova configuração do trabalho docente em que o professor se vê obrigado a corresponder, tendo em vista as exigências avaliativas que poderá gerar consequências para o seu prestígio e 
reconhecimento profissional, autoestima, progressão na carreira e melhoria salarial, entre outros.

É preciso ter a clareza que o elenco de padrões de desempenhos de referência nacional (perfis profissionais) estabelecidos para a categoria docente pouco dão conta da complexidade, variedade, historicidade e natureza do trabalho de professor, por isso tais padrões podem ser entendidos como fruto de uma seleção arbitrária daquilo que, em determinados contextos e sociedades, julga-se o mais adequado para regular e monitorar a profissão docente e definir o que seja "um docente de desempenho excelente" ou um docente de qualidade, que na ótica do legislador seria aquele que não só alcançaria todos os objetivos propostos como também os ultrapassaria, gerando impacto positivo no serviço prestado. Tal conduta do professor demonstraria não só possuir competências a um nível mais elevado como também o levar a pensar e a comportar-se à imagem de um ideal de professor, legitimando o grau máximo do saber e do poder, portanto, da excelência. Assim, há de se destacar que tais padrões, embora partam de uma definição do que é ser um docente de desempenho excelente na ótica do governo, revelam uma expectativa/previsão de trabalho padronizada em que os docentes devam corresponder, os quais são limitados, redutores, a-históricos, pois não há como aplicá-los de forma universal em cenários escolares tão diversos, singulares e conflituosos, desconsiderando o projeto educativo da escola, o entorno em que se insere e seus sujeitos.

A investigação no campo da avaliação docente chama a atenção, como adverte Flores (2010), de que esta encontra-se associada a determinadas visões de ensino e de professor e ao modo como estas são traduzidas em padrões, critérios e indicadores de avaliação. Inevitavelmente, e como acontece em tantos outros países, os perfis profissionais exigidos na ADD em Portugal revelam que a concepção que subjaz a essa avaliação diz respeito à comparação de conhecimentos, destrezas, atitudes e responsabilidades a um ideal de professor, que na ótica do legislador, seria a de um docente de desempenho excelente, ou a do professor necessário para intervir positivamente na realidade portuguesa. Validar competências, 
regular a prática docente, avaliar o desempenho profissional são mecanismos de que o Estado lança mão para distinguir desempenhos, diferenciar méritos e discriminar qualidade (de forma positiva ou negativa) daqueles professores que demonstrem um maior nível de excelência, compromisso, responsabilidade, eficiência e eficácia em situação de profissionalidade, embora pouco se tenha fiabilidade de que essa avaliação vai, de fato, converter-se em melhoria da prática docente, do ensino e das aprendizagens dos alunos. Esse ainda é o grande desafio da ADD em Portugal. Nesse sentido, podemos afirmar:

- o elenco de padrões de desempenho docente não tem como prever determinadas circunstâncias possíveis em que o trabalho do professor se realiza e por ele é avaliado;

- pergunta-se se faz sentido padrões de desempenho docente de referência nacional, aplicável de forma universal a todos os professores, se a realidade educativa vivida em cada escola é contextual, histórica e singular, o que faz com que o trabalho docente oscile mediante a ela;

- os padrões de desempenho docente podem ser interpretados como uma forma de controle, regulação e monitoramento nacional da profissão docente pelo estado;

- a avaliação docente, baseada em padrões de desempenho, não pode garantir e nem assegurar que se produza um tipo de resultado positivo (ou não) junto aos professores em termos de melhoria de suas práticas e da aprendizagem dos alunos.

Em síntese, a ADD é complexa, pois transita em um campo de subjetividades e concepções cujas práticas em Portugal têm revelado seus dissensos e conflitos, todavia é possível, e, sobretudo, desejável, quando é orientada por princípios avaliativos de natureza educativa, e não seletiva. A análise dos PDD como referência para a ADD em Portugal revela que há uma teoria educacional em causa, embora não esteja lá claramente explicitada, que orienta a efetivação de 
um trabalho docente numa perspectiva de competências cuja referência máxima é o grau de excelência que pode ser alcançado pelo professor. Isso implica considerar em uma dada teoria educacional quais as finalidades do ensino, da escola, da sociedade e do homem que o projeto educacional pretende desenvolver. Entender quais projetos educacionais estão na ordem do dia no cenário português, identificando suas contribuições para uma sociedade mais justa e igualitária, nos ajudaria melhor a construir ou fazer opções por projetos educacionais que visem a tais objetivos. Assim, questiona-se: que formação e profissionalização se esperam para o professor português nesse contexto de profundas mudanças na base produtiva do país?

\section{REFERÊNCIAS}

ALVES, Maria Palmira; MACHADO, Eusébio André. 0 pólo de excelência: caminhos para a avaliação do desempenho docente. Porto: Areal Editores, 2010.

COUTO, Lúcia de Fátima Monteiro. Implementação do novo modelo de avaliação do desempenho docente. A perspectiva de professores de uma E.B. 2/3 Ciclos entre 2001 e 2009. Dissertação (Mestrado em Educação) - Instituto de Educação da Universidade de Lisboa, Lisboa, 2010.

CURADO, Ana Paula. Política de avaliação de professores em Portugal: um estudo de implementação. Lisboa: Fundação Calouste Gulbenkian, 2002.

DALILA, Andrade Oliveira. A reestruturação do trabalho docente: precarização e flexibilização. Educação e Sociedade - Cedes, Campinas, v. 25, n. 89, p. 1203-1225, set./dez. 2004.

DE KETELE, Jean-Marie. A avaliação do desenvolvimento profissional dos professores: postura de controle ou postura de reconhecimento. In: ALVES, Maria Palmira; MACHADO, Eusébio André. 0 pólo de excelência: caminhos para a avaliação do desempenho docente. Porto: Areal Editores, 2010.

FERNANDES, Domingos. Avaliação do desempenho docente: desafios, problemas e oportunidades. Cacém: Texto Editores, 2008.

FLORES, Maria Assunção. A avaliação de professores numa perspectiva internacional: sentidos e implicações. Porto: Areal Editores, 2010.

FORMOSINHO, João; MACHADO, Joaquim. Os professores e a diferenciação docente: da especialização de funções à avaliação de desempenho. In: FORMOSINHO, João; MACHADO, Joaquim; OLIVEIRA-FORMOSINHO, Júlia. Formação, desempenho e avaliação de professores. Mangualde: Edições Pedago, 2010a. 
Desempenho, mérito e desenvolvimento: para uma avaliação mais profissional dos professores. In: FORMOSINHO, João; MACHADO, Joaquim; OLIVEIRA-FORMOSINHO, Júlia. Formação, desempenho e avaliação de professores. Mangualde: Edições Pedago, 2010b.

GATTI, Bernardete. Avaliação de professores: um campo complexo. Estudos em Avaliação Educacional, São Paulo, v. 22, n. 48, p. 77-88, jan./abr. 2011.

GIROUX, Henry. Tempo público e esperança educada: liderança educacional e a guerra contra os jovens. Mangualde: Pedago, 2007.

MOREIRA, Maria Alfredo. O lugar da observação na avaliação docente: o que vale o que observamos. In: ALVES, Maria Palmira; FLORES, Maria Assunção; MACHADO, Eusébio André. Quanto vale o que fazemos? Práticas de avaliação de desempenho. Santo Tirso: De Facto Editores, 2011.

MOURA, Paulo Veiga. A avaliação do desempenho na administração pública: comentário à Lei n. 66-B/2007, de 28 de dezembro. Coimbra: Coimbra, 2012.

MURILLO JAVIER, Torrecilla. Evaluación del desempeño y carrera profesional docente: un estudio comparado entre 50 países de América y Europa. Santiago: Unesco/Orealc, 2007.

NUNES, Cely do Socorro Costa. As reações dos professores portugueses frente à política de avaliação do desempenho docente: tensões e desafios. Ver a Educação, Belém, UFPA, v. 12, p. 199-212, 2011.

NUNES, Cely do Socorro Costa; RODRIGUES, Pedro. A (in)evitabilidade da avaliação do desempenho docente em Portugal: processos, tensões e desafios. In: FERNANDES, Domingos (Org.). Avaliação em Educação: olhares sobre uma prática social incontornável. 1. ed. Pinhais, PR: Melo, 2011. v. 1, p. 167-184.

PEREIRA, Íris Susana Pires. Avaliação fria, avaliação quente. Contributos para a discussão da complexidade do processo de avaliação de desempenho docente. In: ALVES, Maria Palmira; FLORES, Maria Assunção; MACHADO, Eusébio André. Quanto vale o que fazemos? Práticas de avaliação de desempenho. Santo Tirso, DE FACTO Editores, 2011.

PORTUGAL. Assembleia da República. Lei n. 66-B/2007, de 28 de dezembro. Estabelece o sistema integrado de gestão e avaliação de desempenho na Administração Pública.

PORTUGAL. Ministério da Educação. Gabinete da Ministra. Despacho n. 16034/2010. Estabelece padrões de desempenho docente.

Ministério da Educação e Ciência. Gabinete do Ministro. Despacho n. 17169/2011. Decreta que o documento Currículo Nacional do Ensino Básico - Competências Essenciais deixa de se constituir documento orientador do Ensino Básico em Portugal.

Ministério da Educação e Ciência. Gabinete do Ministro. Despacho n. 5306/2012a, que cria o grupo de trabalho de reformulação das Metas Curriculares.

Ministério da Educação e Ciência. Decreto-Lei n. 41/2012b, de 21 de fevereiro. Altera o Estatuto da Carreira dos educadores de infância e dos professores dos ensinos básico e secundário. 
. Ministério da Educação e Ciência. Decreto Regulamentar n. 26/2012c, de 21 de fevereiro. Institui um novo regime de avaliação do desempenho docente aos educadores de infância e dos professores dos ensinos básico e secundário.

POSADA, Juan A. Castro. La evaluación de los profesores: trivializar la evaluación o evaluar lo trivial? In: RUIVO, João; TRIGUEIROS, António. Avaliação de desempenho de professores. RVJ Editores, Associação Nacional de Professores, 2009.

SAMPAIO, Maria das Mercês Ferreira; MARIN, Alda Junqueira. Precarização do trabalho docente e seus efeitos sobre as práticas curriculares. Revista Educação e Sociedade - Cedes, Campinas, v. 25, n. 89, p. 1203-1225, set./dez. 2004.

SANTOS, Albertina Lopes Pires. Avaliação do desempenho docente em Portugal: que impactos? Perceção dos professores de uma escola do $3^{\circ}$ ciclo. Dissertação (Mestrado em Educação) - Instituto de Educação da Universidade de Lisboa, Lisboa, 2012.

SIMÕES, G. A. A avaliação dos professores como estratégia de desenvolvimento profissional e organizacional. Dissertação (Mestrado em Educação) - Faculdade de Psicologia e Ciências da Educação da Universidade de Lisboa, Lisboa, 1998.

VIEIRA, Flávia; MOREIRA, Maria Alfredo. Supervisão e avaliação do desempenho docente: para uma abordagem de orientação transformadora. Ministério de Educação. Lisboa: Conselho Científico para a Avaliação de Professores: Cadernos CCAP-1. 2011.

\section{CELY DO SOCORRO COSTA NUNES}

Doutora em Educação. Instituto de Educação da Universidade

de Lisboa - Portugal

csnunes@ie.ul.pt 